\title{
Rice bran fermentation by lactic acid bacteria to enhance antioxidant activities and increase the ferulic acid, $\rho$-coumaric acid, and $\gamma$-oryzanol content
}

\author{
Bao Le ${ }^{1} \cdot$ Pham Thi Ngoc Anh ${ }^{1} \cdot$ Jung-Eun $\mathrm{Kim}^{2} \cdot$ Jinhua Cheng ${ }^{2} \cdot$ Seung Hwan Yang ${ }^{1}$ (D)
}

Received: 19 July 2019 / Accepted: 5 August 2019 / Published Online: 30 September 2019

(C) The Korean Society for Applied Biological Chemistry 2019

\begin{abstract}
Rice bran is considered a natural source of antioxidants. In this study, rice bran was fermented with lactic acid bacteria to increase its antioxidant activity. Four strains isolated from fermented food, Lactobacillus plantarum MJM60383, Lactococcus lactis subsp. lactis MJM60392, Lactobacillus fermentum MJM60393, and Lactobacillus paracasei MJM60396, were confirmed as safe through stability tests such as safety assessment for biogenic amine production, hemolytic activity, and mucin degradation, and showed high reducing capacity. The antioxidant activity of rice bran fermentation altered by these strains was evaluated using several methods including measurement of $\mathrm{Fe}^{2+}$ chelating activity and scavenging activity by 1,1-diphenyl-2-picryl-hydrazil (DPPH), 2,2'-azinobis-(3-ethylbenzothiazoline-6-sulfonic acid) (ABTS), and nitric oxide assays. In this study, the total phenolic content and $\gamma$-oryzanol were evaluated by high-performance liquid chromatography. Compared to non-fermented rice bran and a commercial product, rice bran fermented with Lactococcus lactis subsp. lactis MJM60392 showed the highest phenolic content (844.13 mg GAE/g). Moreover, the content of ferulic acids, $\rho$ coumaric acid, and $\gamma$-oryzanol in rice bran increased after fermentation with L. lactis subsp. lactis MJM60392 and $L$.
\end{abstract}

Seung Hwan Yang $(\bowtie)$

E-mail: ymichigan@jnu.ac.kr

Jinhua Cheng $(\bowtie)$

E-mail: jhcheng316@mju.ac.kr

${ }^{1}$ Department of Biotechnology, Chonnam National University, Yeosu 59626, Republic of Korea

${ }^{2}$ Division of Bioscience and Bioinformatics, College of Natural Science, Myongji University, Yongin 17058, Republic of Korea

This is an Open Access article distributed under the terms of the Creative Commons Attribution Non-Commercial License (http://creativecommons. org/licenses/by-nc/3.0/) which permits unrestricted non-commercial use, distribution, and reproduction in any medium, provided the original work is properly cited. fermentum MJM60393 compared to other samples. Indeed, the DPPH radical scavenging activity and NO scavenging activity were also found to be high in these fermented rice brans. These results indicated that fermentation with lactic acid bacteria increases the active compound levels and the potent antioxidant activities of rice bran.

Keywords Antioxidant $\cdot$ Lactobacillus $\cdot$ Phenolic $\cdot$ Rice bran

\section{Introduction}

Plants naturally synthesize medicinal compounds such as phytochemicals, which are biologically active compounds present in the roots and leaves of plants [1]. Phytochemicals have been used since a long time to prevent and treat various human diseases [2], and are divided into three major groups: terpenoids, phenolics, and alkaloids [3]. According to numerous studies, cancer risk is lowered when people consume large amounts of fruits and vegetables [4]. Therefore, consumption of plant-based foods may help prevent cancer, increase antioxidant activity, reduce blood cholesterol, lower inflammatory activity, and inhibit cholesterol oxidation $[5,6]$.

Rice bran is a by-product of the rice milling process and includes the pericarp, testa, nucleus, aleurone layer, and embryo of the rice grain. It contains approximately $95 \%$ of the nutrients in rice, with the aleurone layer containing high levels of bioactive compounds [7]. Rice bran has many beneficial health effects such as anticarcinogenic, cholesterol-lowering, anti-hypertensive, anti-cancer, anti-allergy, and antioxidant activities [8-10]. Rice bran contains natural antioxidant compounds such as $\gamma$-oryzanol (0.9-2.9\%), vitamin $\mathrm{E}(0.1-0.14 \%)$ compounds such as tocopherols $(\alpha, \beta, \gamma$, and $\delta$ ) and tocotrienols $(\alpha, \beta$, and $\gamma)$, carotenoids, and phenolic acids [11]. Although rice bran contains many natural antioxidant 
components and nutritional proteins, its potential application as a natural material for preparing functional foods is limited because of its high insolubility, high fiber content, and possible hull contamination $[12,13]$. The main phenolic compounds in the rice bran layer are phenyl propanoids, which include hydroxycinnamic acids (gallic acid, vanillic acid, hydroxybrnzoic acid, and syringic acid) and hydroxybenzoic acid (caffeic acid, chlorogenic acid, ferulic acid, p-coumaric acid, and sinapic acid) derivatives [14] These compounds are present as soluble free phenolic acids and insoluble bound phenolic acids. The human body cannot digest the insoluble bound phenolic acids.

Fermentation using lactic acid bacteria (LAB) can hydrolyze the insoluble bound phenolic acids to soluble phenolic acids through the activities of various enzymes such as cellulase, esterase, and decarboxylase to hydrate the insoluble bound phenolic acids $[15,9]$. The levels of nutrients such as folates, soluble dietary fiber, and total content of phenolic compounds in cereals can be increased by cereal-based LAB fermentation [16]. Many studies have shown that fermentation using probiotics can increase the content of active compounds and antioxidant compounds included in rice bran $[17,18]$. Thus, many companies have introduced various fermented rice bran products to the market.

However, though the currently available fermented rice bran products are healthy, they are not satisfactory enough in terms of functional and nutritional properties. The purpose of this study was to develop a novel functional rice bran product fermented with different LAB. After the fermentation process, the phenolic acid and hydroxybenzoic acid content was determined. Moreover, rice bran fermented with the selected LAB strains was investigated to determine the antioxidant activities and was compared to a commercial rice bran product $\mathrm{A}$ to evaluate its potential for application as a functional food.

\section{Materials and Methods}

\section{Screening for safety assessment of LAB}

All 150 LAB strains used in the study were previously isolated from traditional fermented foods (including yogurt, kefir, cheese, kimchi, and jeotgal) and were obtained from the culture collection of the microbiology laboratory of Chonnam National University. Hemolytic activity was determined as described by Taixera (2014). Briefly, LAB strains were streaked onto Columbia agar plates (Difco, Detroit, MI, USA) containing 5\% (vol/vol) defibrinated sheep blood (Medexx Co., Ltd., Gyeonggi-do, Korea). After incubation at $37^{\circ} \mathrm{C}$ for $24 \mathrm{~h}$, negative hemolysis activity was observed as the absence of a clear zone around colonies. The biogenic amine method was carried out as described by BoverCid, Holzapfel [19]. The LAB strains were incubated in decarboxylase agar (Difco) with or without amino acids at $37{ }^{\circ} \mathrm{C}$ for $24 \mathrm{~h}$. Positive activity was indicated by the formation of a purple halo around a colony. Mucinolytic activity was assessed as described by Le, Yang [20]. All experiments were performed at least three times. Only 27 LAB strains were selected as safe for human consumption and were evaluated further to determine their reducing power capacities.

\section{Screening for antioxidant activity by reducing power capacity} The reducing activity of rice bran extracts was analyzed as described by Oyaizu [21]. An overnight LAB culture was adjusted to $\mathrm{OD} 600 \mathrm{~nm}$ of 0.5 followed by centrifugation at $3,000 \times \mathrm{g}$ for $20 \mathrm{~min}$. The cell-free supernatant was then mixed with $1 \%$ potassium ferricyanide solution. The mixture was incubated with $10 \%$ trichloroacetic acid (w/v) at $50{ }^{\circ} \mathrm{C}$ for $25 \mathrm{~min}$. The upper layer was harvested by centrifugation at $150 \times g$ for $10 \mathrm{~min}$ and mixed with $5 \mathrm{~mL}$ deionized water and $1 \mathrm{~mL}$ of $0.1 \%$ ferric chloride. Finally, the OD $700 \mathrm{~nm}$ of the upper layer was measured after $20 \mathrm{~min}$ and ascorbic acid was used as a positive control.

\section{Preparation of rice bran fermentation}

Four LAB isolates, Lactobacillus plantarum MJM60383, Lactococcus lactis subsp. lactis MJM60392, Lactobacillus fermentum MJM60393, and Lactobacillus paracasei MJM60396, were grown on MRS agar plates and subcultured in MRS broth at $37^{\circ} \mathrm{C}$ for $24 \mathrm{~h}$ under aerobic conditions before fermentation. The rice bran used in this study was purchased from Inno-Nutribio (Seoul, Korea). A milled rice bran sample was passed through a $250-\mu \mathrm{m}$ sieve. Rice bran $(100 \mathrm{~g})$ was then homogenized with $25 \mathrm{~mL}$ nutrient solution ( $2 \mathrm{~g} \mathrm{~L}^{-1} \mathrm{KH}_{2} \mathrm{PO}_{4}, 1 \mathrm{~g} \mathrm{~L}^{-1} \mathrm{MgSO}_{4}, 8 \mathrm{~g} \mathrm{~L}^{-1} \mathrm{NH}_{2} \mathrm{CONH}_{2}$ in $0.4 \mathrm{~N}$ $\mathrm{HCl})$ in tray bioreactors. The reactors were heated at $121^{\circ} \mathrm{C}$ for 15 min and then cooled to room temperature. The inoculum of the four LAB strains was added separately and incubated at $37^{\circ} \mathrm{C}$ in a fermentation chamber with controlled humidity. After $24 \mathrm{~h}$ of fermentation, the rice brain residues were extracted, and then their antioxidant activity and bioactive compound content were determined.

\section{Fermented rice bran extraction}

Fermented rice bran was extracted as described by Lister, Wilson [22]. Samples of $5 \mathrm{~g}$ were subjected to orbital shaking (150 rpm) at room temperature for $3 \mathrm{~h}$ with methanol and the obtained extract was filtered through filter paper (Whatman no. 4) into a separating funnel. The methanolic extract was evaporated on a rota-evaporator at $50{ }^{\circ} \mathrm{C}$ under reduced pressure and was then resuspended in $10 \mathrm{~mL}$ of distilled water followed by placing in an ultrasonic bath for $10 \mathrm{~min}$. The resulting extract was clarified with $5 \mathrm{~mL}$ of $0.1 \mathrm{M} \mathrm{ZnSO}_{4}$ and $5 \mathrm{~mL}$ of $0.1 \mathrm{M} \mathrm{Ba}(\mathrm{OH})_{2}$, and was allowed to rest for $20 \mathrm{~min}$. After centrifugation $\left(10 \mathrm{~min}, 25^{\circ} \mathrm{C}\right.$, $3,200 \times g$ ), the supernatant containing the phenolic compounds was collected, lyophilized, and quantified spectrophotometrically at $750 \mathrm{~nm}$ with Folin-Ciocalteu reagent (Qell, Brazil) using gallic acid (Sigma, St. Louis, MO, USA) as a standard $(2-20 \mathrm{~g} / \mathrm{mL})$. Each sample extract was diluted with $25 \%$ methanol for antioxidant activity measurement. 


\section{Analysis of phenolic acids and $\gamma$-oryzanol content}

All methanolic extracts were filtered through a $0.25-\mu \mathrm{m}$ syringe filter before use. Phenolic acid compounds were quantified by high-performance liquid chromatography (HPLC; Series 1200, Agilent Technologies, Santa Clara, CA, USA) coupled with a C18 column $(250 \mathrm{~nm} \times 4.6 \mathrm{~mm}$ i.d., $5 \mu \mathrm{m}$, YMC-Pack ODS AM (YMC Co. Ltd., Kyoto, Japan). The mobile phase was $100 \%$ methanol (solvent $\mathrm{A}$ ) and distilled water with $0.2 \%$ glacial acetic acid (solvent B), flow rate was $1 \mathrm{~mL} / \mathrm{min}$, and injection volume was $20 \mu \mathrm{L}$. The mobile phase used to evaluate ã-oryzanol was methanol/acetonitrile/acetic acid (52:45:3 v/v) and the flow rate was set to $0.8 \mathrm{~mL} / \mathrm{min}$. The eluent band of phenolic acids ( $\rho-$ coumaric acid and ferulic acid) was detected at a wavelength of $325 \mathrm{~nm}$, whereas $\gamma$-oryzanol was detected at $325 \mathrm{~nm}$. The results were compared to those obtained using a non-fermented (NA) sample and commercial product A. As stated on the label claim, the composition of commercial product $\mathrm{A}$ is as follows: germinated brown rice $(30 \%)$, rice bran $(65 \%)$, four kinds of $\mathrm{LAB}(4.7 \%)$, and biominerals $(0.3 \%)$.

\section{Determination of antioxidant activity}

The ABTS free radical scavenging activity assay was performed as described previously [23]. First, $7 \mathrm{mM}$ 2,2'-azinobis-(3ethylbenzothiazoline-6-sulfonic acid (ABTS) solution was mixed and incubated with $2.4 \mathrm{mM}$ potassium persulfate for $16 \mathrm{~h}$ at room temperature in the dark. The mixture was diluted by mixing $1 \mathrm{~mL}$ ABTS solution with distilled water to obtain an absorbance of $0.70 \pm 0.02$ units at $734 \mathrm{~nm}$ measured using a UV/Vis spectrophotometer. Sample extracts $(10 \mu \mathrm{L})$ were reacted with $190 \mu \mathrm{L}$ of ABTS solution for $3 \mathrm{~min}$ in the dark. Absorbance was measured at $734 \mathrm{~nm}$ using a UV/Vis spectrophotometer. A blank was prepared without the extract. Ascorbic acid was used as a standard. The scavenging activity was derived following Eq. (1):

Inhibition of ABTS activity (\%) $=[1-($ A734 nm sample $/$ A734 nm, blank $)] \times 100$

1,1-Diphenyl-2-picryl-hydrazil (DPPH) radical scavenging was evaluated as described by Brand-Williams et al. [24]. Each sample extract was mixed with $25 \%$ methanol and $0.1 \mathrm{mM} \mathrm{DPPH}$ solution. After $30 \mathrm{~min}$ in the dark, the absorbance of the mixture was measured at $517 \mathrm{~nm}$. The inhibition percentage of DPPH absorbance was calculated using Eq. (2):

$$
\begin{aligned}
& \text { Inhibition of DPPH activity (\%) } \\
& \quad=[1-(\text { A517 nm sample/A517 nm blank })] \times 100
\end{aligned}
$$

Inhibition of nitric oxide (NO) was determined according to the method of Marcocci et al. [25]. The extract was heated to $37{ }^{\circ} \mathrm{C}$ for $1 \mathrm{~h}$. The incubated solution was mixed with Griess reagent ( $1 \%$ sulfanilamide, $2 \% \mathrm{H}_{3} \mathrm{PO}_{4}$, and $0.1 \%$ naphthyl ethylenediamine dihydrochloride). The mixture was then incubated for $5 \mathrm{~min}$ in the dark and absorbance was measured at $540 \mathrm{~nm}$. NO inhibition was calculated based on Eq. (3):

$$
\begin{aligned}
& \text { Inhibition of NO activity (\%) } \\
& \quad=[1-(\text { A540 nm sample/A540 nm blank })] \times 100
\end{aligned}
$$

The $\mathrm{Fe}^{2+}$ chelating activity of the extract was determined as described previously [26]. The reaction mixture contained $1 \mathrm{~mL}$ of each extract solution with $3.7 \mathrm{~mL}$ of methanol and $0.1 \mathrm{~mL}$ of $2 \mathrm{mM}$ ferrous chloride. Subsequently, $0.2 \mathrm{~mL}$ of $5 \mathrm{mM}$ ferrozine was added to the mixture and reacted for $10 \mathrm{~min}$ at room temperature. The $\mathrm{Fe}^{2+}$ chelating activity of the solution was measured spectrophotometrically at $562 \mathrm{~nm}$ and expressed according to Eq. (4):

$$
\begin{aligned}
& \text { Inhibition } \mathrm{Fe}^{2+} \text { chelating activity }(\%) \\
& \quad=[1-(\mathrm{A} 562 \mathrm{~nm} \text { sample/A562 } \mathrm{nm} \text { blank })] \times 100
\end{aligned}
$$

\section{Statistical analyses}

All data were collected in triplicate and the means were used for statistical analysis. Analysis of variance and Duncan's multiple range post-hoc test were performed using Statistical Analysis System software (SAS 9.0, SAS Institute, Cary, NC, USA) with a confidence interval of $95 \%(p<0.05)$ and $99 \%(p<0.01)$.

\section{Results and Discussion}

\section{Isolation of $\mathrm{LAB}$ and reducing power of $\mathrm{LAB}$}

To select the starter rice bran culture candidates, $150 \mathrm{LAB}$ strains isolated from several fermented sources were evaluated. Of these, 27 strains passed safety tests such as biogenic amine production, hemolytic activity, and mucin degradation analyses. These strains were further tested for their reducing power activities. Figure 1 shows the reducing power activities of these strains; four strains, L. plantarum MJM60383, L. lactis subsp. lactis MJM60392, L. fermentum MJM60393, and L. paracasei MJM60396, showed high activities and were selected as potential starter strains for rice bran fermentation. Previous studies have shown that lactobacilli have strong antioxidant activities; however, the reducing capacity of LAB varies considerably among different strains depending on their metabolites $[27,28]$. Some LAB strains such as L. plantarum can produce L-3-(4-hydroxyphenyl) lactic acid and L-indole-3lactic acid, which exhibit radical scavenging activity [29].

\section{Total phenolic content}

The total phenolic content was determined based on the FolinCiocalteu reagent method and the results were expressed as gallic acid equivalents (GAEs) (Fig. 2A). The non-fermented rice bran showed a phenolic compound content of $609.44 \mathrm{mg} \mathrm{GAE} / \mathrm{g}$, which was lower than that in the rice bran fermented with all four strains. Rice bran fermented with Lactococcus lactis subsp. lactis MJM60392 contained the highest phenolic content of $844.13 \mathrm{mg}$ GAE/g compared to $186.25 \mathrm{mg}$ GAE/g in product A. This is similar to the value reported for rice bran fermented with Rhizopus oryzae [30]. The increased phenolic content can be explained by 


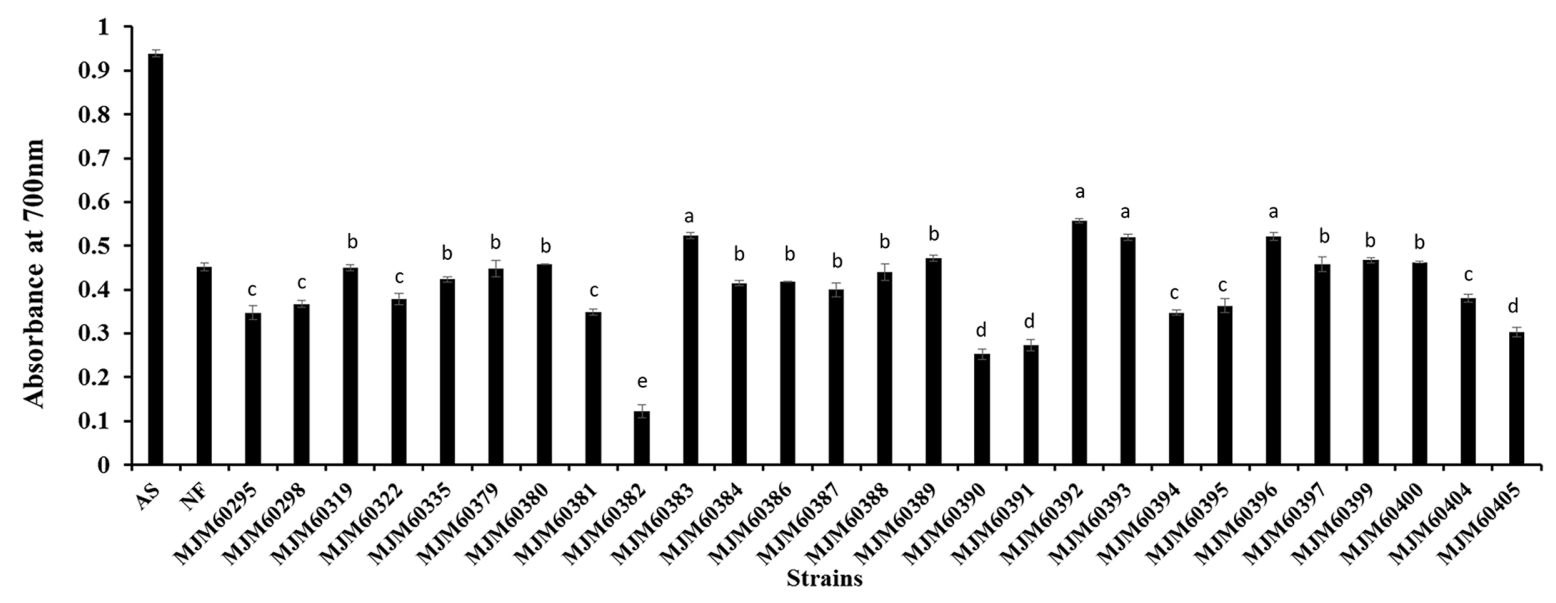

Fig. 1 Screening strains for reducing power of lactic acid bacteria. The data are presented as the mean $\pm \mathrm{SD}(\mathrm{n}=3)$. Values with different superscripts are significantly different at $p<0.05$. AS, ascorbic acid; NF, non-fermented rice bran

(A)

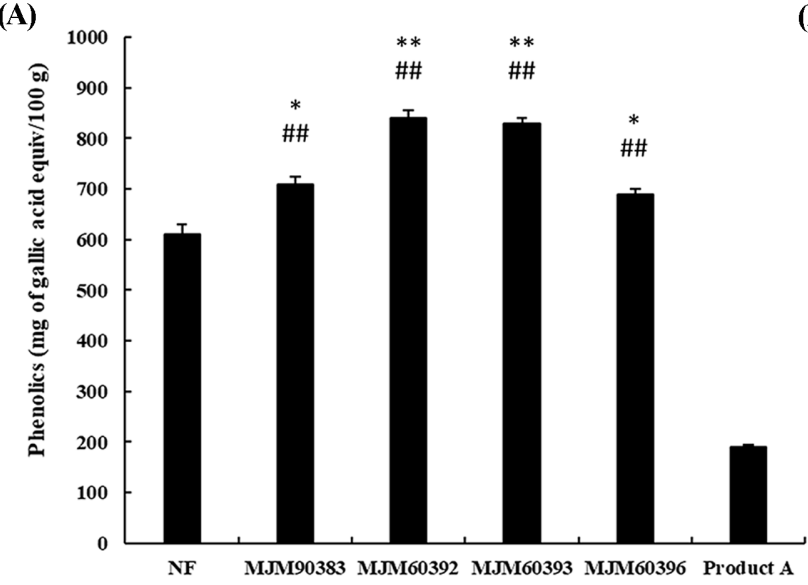

(C)

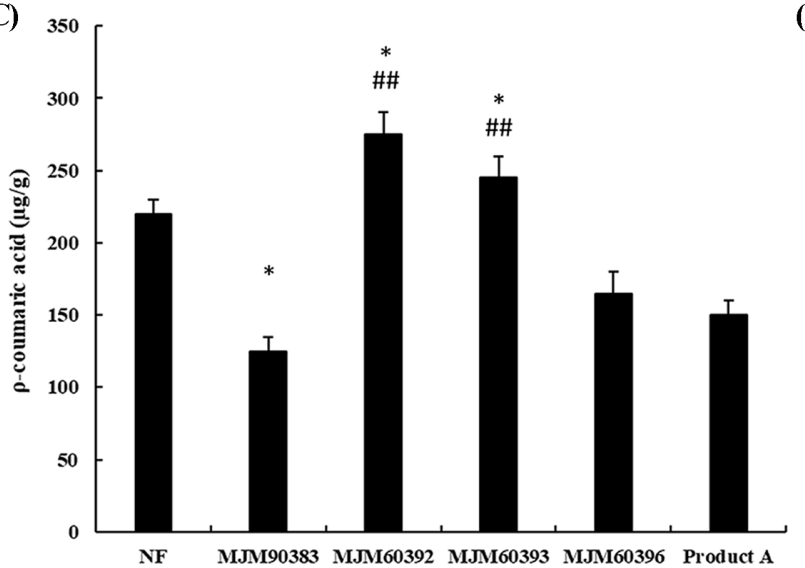

(B)

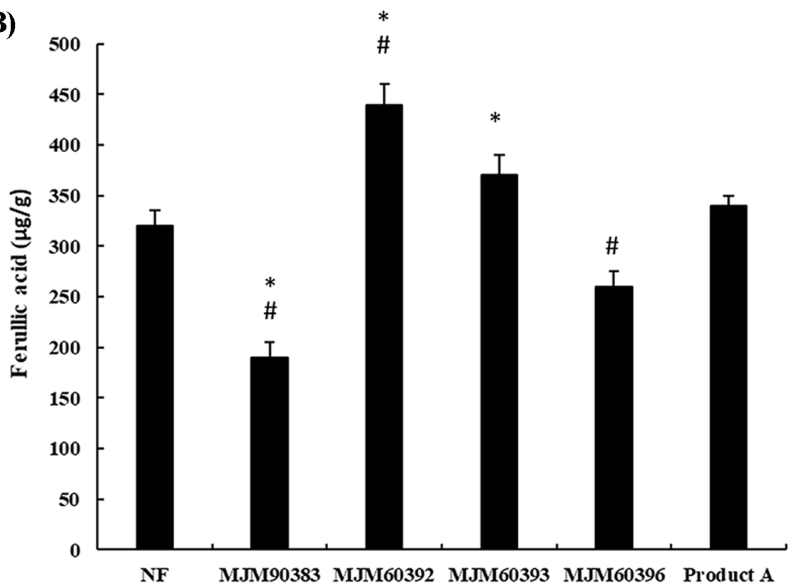

(D)

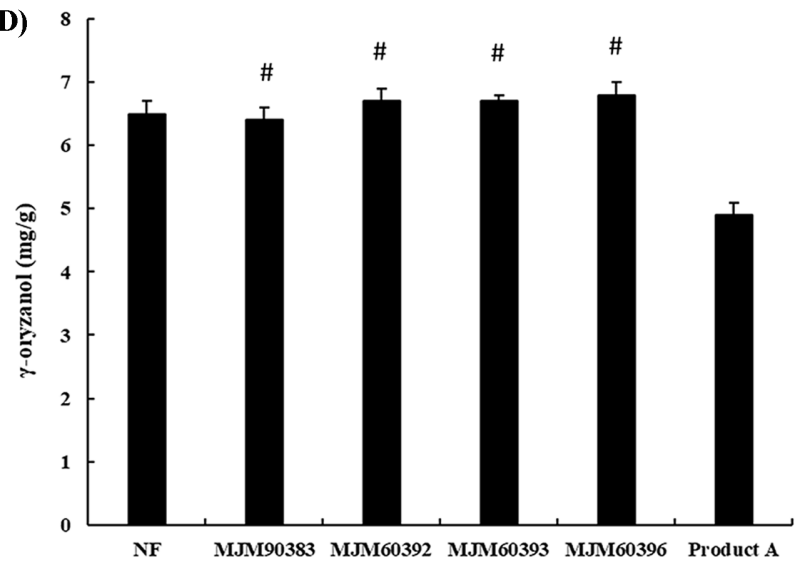

Fig. 2 Bioactive compounds content by phenolic extracts of fermented rice bran with different lactic acid bacteria. (A) Total phenolic contents, (B) bound ferulic acids, (C) $\rho$-coumaric acid, and (D) $\gamma$-oryzamol acid. ${ }^{*} p<0.05,{ }^{* *} p<0.01$ vs. the NF; ${ }^{\#} p<0.05,{ }^{\#} p<0.01$ vs. product A (n=3). NF, nonfermented rice bran 


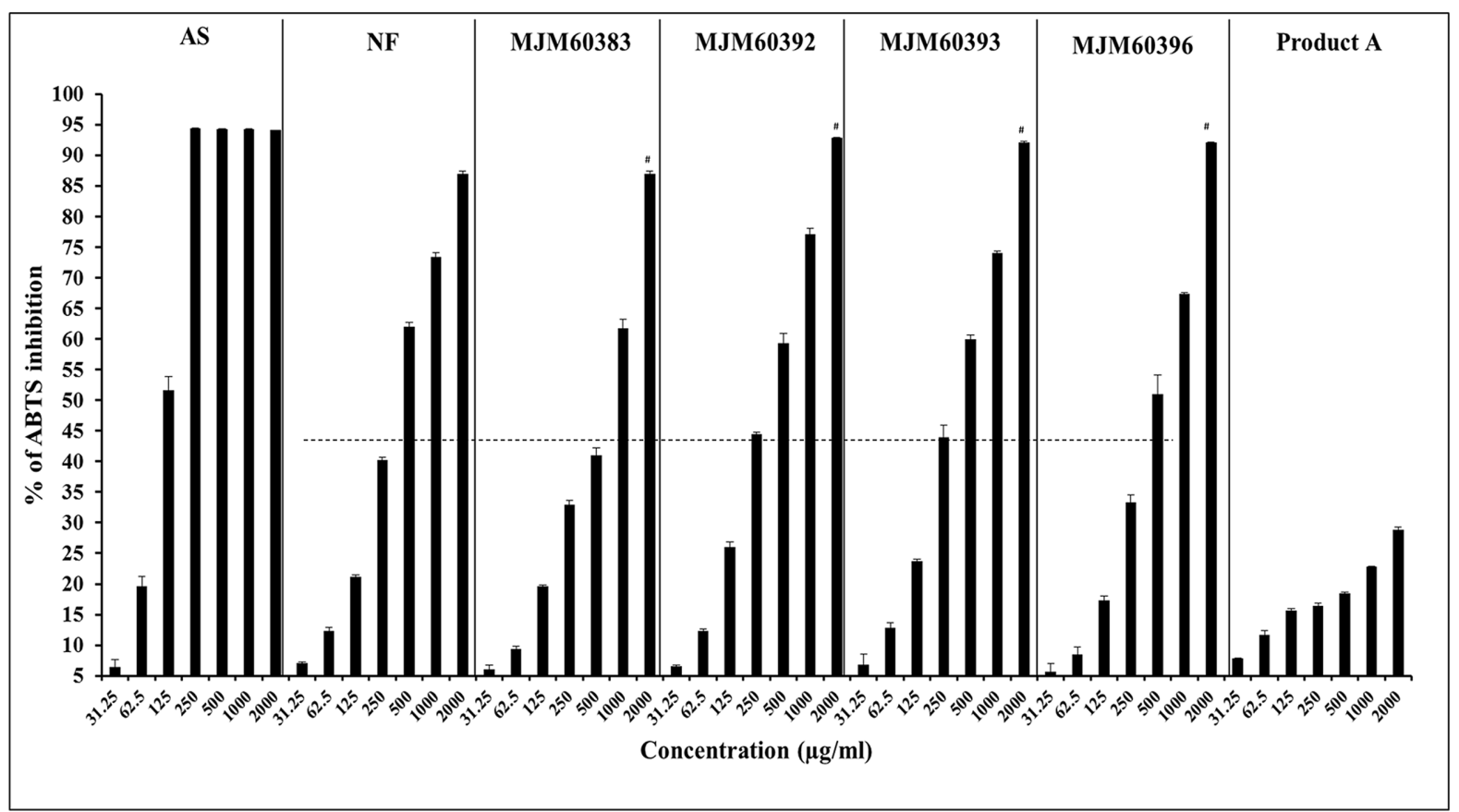

Fig. 3 ABTS free radical scavenging activity by phenolic extracts of fermented rice bran with different lactic acid bacteria. $* p<0.05$ vs. the NF; ${ }^{\#} p<0.05$ vs. product A ( $\left.\mathrm{n}=3\right)$. AS, ascorbic acid; NF, non-fermented rice bran

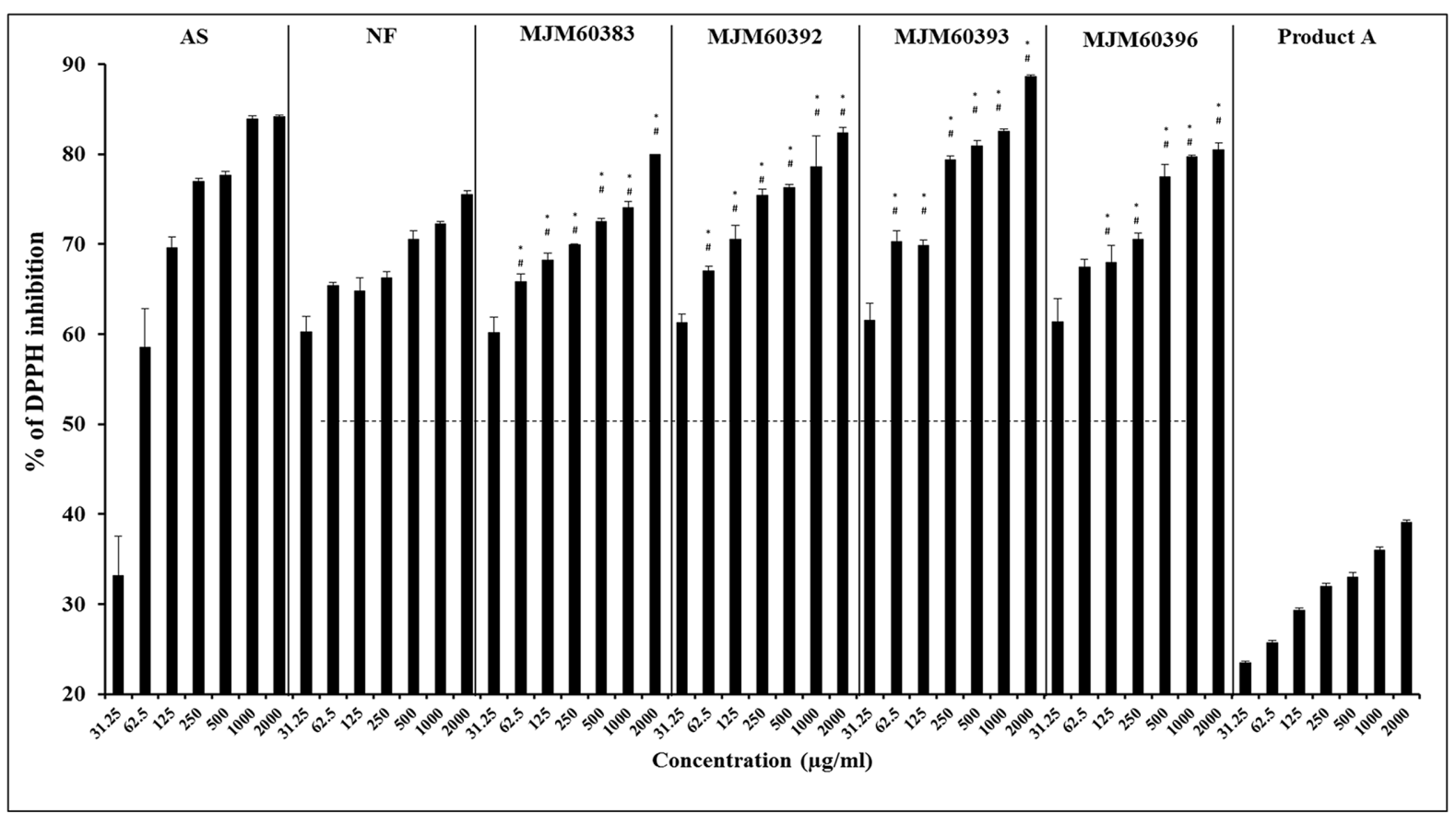

Fig. 4 DPPH free radical scavenging activity by phenolic extracts of fermented rice bran with different lactic acid bacteria. $* p<0.05$ vs. the NF; ${ }^{\#} p<0.05$ vs. product $\mathrm{A}(\mathrm{n}=3)$. AS, ascorbic acid; NF, non-fermented rice bran

the higher levels of $\beta$-glucosidase enzymes and esterases produced by LAB during fermentation $[15,9,18]$.

Ferulic acids, $\rho$-coumaric acid, and $\gamma$-oryzanol

Ferulic acids, $\rho$-coumaric acid, and $\gamma$-oryzanol positively affect antioxidant activity. The content of these compounds was determined by HPLC analysis and the results are shown in Fig. 2B-D. The content of ferulic acids, $\rho$-coumaric acid, and $\gamma$ oryzanol was higher in the rice bran fermented with L. lactis subsp. lactis MJM60392 and L. fermentum MJM60393 than in 


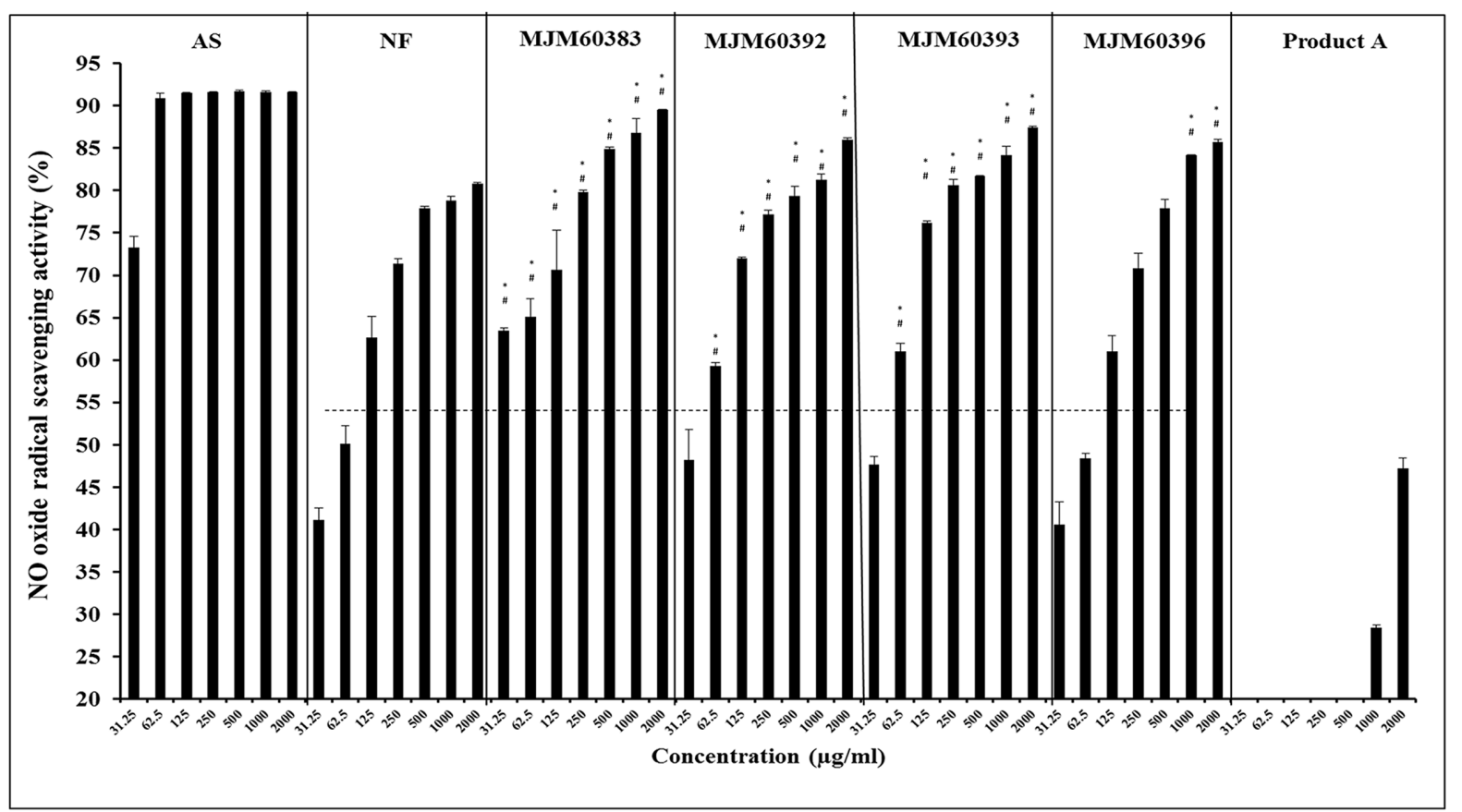

Fig. 5 Nitric oxide $(\mathrm{NO})$ scavenging activity by phenolic extracts of fermented rice bran with different lactic acid bacteria. ${ }^{*} p<0.05$ vs. the NF; ${ }^{\#} p<0.05$ vs. product A $(\mathrm{n}=3)$. AS, ascorbic acid; NF, non-fermented rice bran

other samples. Ferulic acid is an extremely abundant hydroxycinnamic acid in the plant cell wall and shows the highest antioxidant activity [31]. Some microorganisms such as Aspergillus niger and Lactobacillus acidophilus can produce feruloyl esterase to degrade the esterified ferulate for bioconversion to [15]. These results suggest that rice bran fermented with $L$. lactis subsp. lactis and L. fermentum contains ferulic acid resulting from feruloyl esterase production. The other predominant phenolic acid $\rho$ coumaric acid was also increased during the fermentation process.

\section{Antioxidant activities of $\mathrm{LAB}$-fermented rice bran}

The ABTS free radical scavenging activities of rice bran fermented with different LAB strains are shown in Fig. 3. The ABTS scavenging rate increased with increasing extract concentrations. However, there were no significant differences in the ABTS scavenging activities among non-fermented and fermented rice bran. Sirilun et al (2017) reported that ABTS scavenging activity did not differ significantly in LAB-mediated soybean fermentation but increased the phenolic content including isoflavone.

DPPH radical scavenging assays are based on the transfer of electrons from a donor molecule to a corresponding radical. This is the simplest method for measuring the ability of antioxidants to intercept free radicals. All fermented rice bran extracts showed higher activity than the non-fermented rice bran extracts (Fig. 4). Rice bran fermented with Lactobacillus fermentum MJM60393 showed the highest (88.64\%) DPPH free radical scavenging activity, which was more than 1.2-fold that of the non-fermented rice bran $(75.55 \%)$. The DPPH radical scavenging activities determined in our study are similar to those of most fermented rice brans [32]. In fact, the DPPH radical scavenging activity showed a strong correlation with phenolic compounds [33]. This finding agrees with the results of increased content of ferulic acids and $\rho$-coumaric, which also showed that the LAB culture fermented with rice bran had strong antioxidant activity.

The free radical scavenging activities of all extracts were determined by measuring NO (nitric oxide) scavenging activity and using ascorbic acid as a standard. As shown in Fig. 5, the NO activity of all fermented rice brans was higher than that of nonfermented rice bran. Lactobacillus plantarum MJM60383 showed the highest activity at $2000 \mu \mathrm{g} / \mathrm{mL}(89.54 \%)$. This sample showed a value 1.1-fold higher than that of non-fermented rice bran $(80.82 \%)$. The NO scavenging activities of L. lactis subsp. lactis MJM60392, L. fermentum MJM60393, and L. paracasei MJM60396 were $85.98,87.43$, and $85.70 \%$, respectively.

Chelation of $\mathrm{Fe}^{2+}$ by extracts was estimated as described by Dinis et al. (1994) and the results are shown in Fig. 6. There were no significant differences with the results among the four strains. The results suggest that the antioxidant activity of rice bran and fermented rice brans is not related to the iron-binding capacity.

In summary, fermenting rice bran with LAB is an effective method for increasing antioxidant activity. Among these strains, $L$. lactis subsp. lactis MJM60392 produced large amounts of phenolic compounds compared to the other strains tested, leading to high antioxidant activities. Thus, LAB can be applied in functional foods to improve human health. 


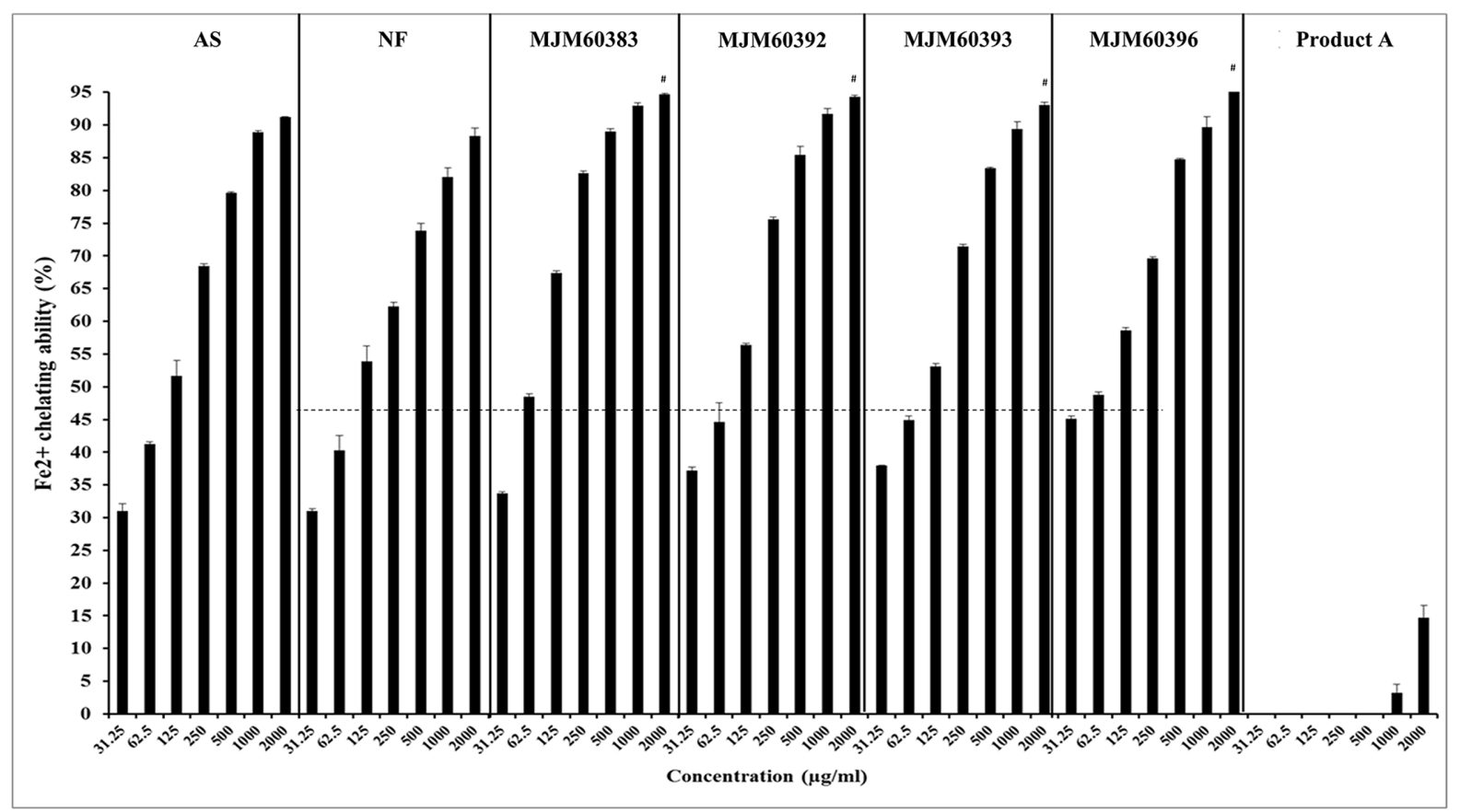

Fig. $6 \mathrm{Fe}^{2+}$ chelating ability by phenolic extracts of fermented rice bran with different lactic acid bacteria. ${ }^{\#} p<0.05$ vs. product $\mathrm{A}$ ( $\mathrm{n}=3$ ). AS, ascorbic acid; NF, non-fermented rice bran

Acknowledgment This study was carried out with the support of the Basic Science Research Program through the National Research Foundation of Korea (NRF) funded by the Ministry of Education (NRF-2017R1D1A3 B03027816).

Conflict of interest statement We declare that we have no conflicts of interest.

\section{References}

1. Wadood A, Ghufran M, Jamal SB, Naeem M, Khan A, Ghaffar R (2013) Phytochemical analysis of medicinal plants occurring in local area of Mardan. Biochem Anal Biochem 2: 1-4

2. Dillard CJ, German JB (2000) Phytochemicals: nutraceuticals and human health. J Sci Food Agric 80: 1744-1756

3. Harborne JB (1999) Classes and functions of secondary products from plants. In: Chemicals from plants: perspectives on plant secondary products. World Scientific, Singapore, pp 1-25

4. Steinmetz KA, Potter JD (1996) Vegetables, fruit, and cancer prevention: a review. J Am Diet Assoc 96: 1027-1039

5. Barbieri R, Coppo E, Marchese A, Daglia M, Sobarzo-Sánchez E, Nabavi SF, Nabavi SM (2017) Phytochemicals for human disease: An update on plant-derived compounds antibacterial activity. Microbiol Res 196: 44-68

6. Zubair H, Azim S, Ahmad A, Khan M, Patel G, Singh S, Singh A (2017) Cancer chemoprevention by phytochemicals: Nature's healing touch. Molecules 22: 395

7. Jeon S, Jeon J, Jeong B (2010) Anti-oxidative activities and tyrosinase inhibition ability of rice bran ethanol extract. J Korean Soc Cosm 16: 602-606

8. Akihisa T, Yasukawa K, Yamaura M, Ukiya M, Kimura Y, Shimizu N, Arai K (2000) Triterpene alcohol and sterol ferulates from rice bran and their anti-inflammatory effects. J Agric Food Chem 48: 2313-2319

9. Donkor ON, Shah NP (2008) Production of $\beta$-Glucosidase and hydrolysis of isoflavone phytoestrogens by Lactobacillus acidophilus, Bifidobacterium lactis, and Lactobacillus casei in soymilk. J Food Sci 73: M15-M20

10. Lee IH, Hung YH, Chou CC (2008) Solid-state fermentation with fungi to enhance the antioxidative activity, total phenolic and anthocyanin contents of black bean. Int J Food Microbiol 121: 150-156

11. Duvernay W, Assad J, Sabliov C, Lima M, Xu Z (2005) Microwave extraction of antioxidant components from rice bran. Pharmaceutical Engineering 25: 126

12. Luh BS, Barber S, de Barber CB (1991) Rice bran: chemistry and technology. In: Rice. Springer, New York, pp 732-781

13. Justo ML, Rodriguez-Rodriguez R, Claro CM, De Sotomayor MA, Parrado J, Herrera MD (2013) Water-soluble rice bran enzymatic extract attenuates dyslipidemia, hypertension and insulin resistance in obese Zucker rats. Eur J Nutr 52: 789-797

14. Sohail M, Rakha A, Butt MS, Iqbal MJ, Rashid S (2017) Rice bran nutraceutics: A comprehensive review. Crit Rev Food Sci Nutr 57: 3771-3780

15. Wang X, Geng X, Egashira Y, Sanada H (2004) Purification and characterization of a feruloyl esterase from the intestinal bacterium Lactobacillus acidophilus. Appl Environ Microbiol 70: 2367-2372

16. Waters DM, Mauch A, Coffey A, Arendt EK, Zannini E (2015) Lactic acid bacteria as a cell factory for the delivery of functional biomolecules and ingredients in cereal-based beverages: a review. Crit Rev Food Sci Nutr 55: 503-520

17. Đorđević TM, Šiler-Marinković SS, Dimitrijević-Branković SI (2010) Effect of fermentation on antioxidant properties of some cereals and pseudo cereals. Food Chem 119: 957-963

18. Hole AS, Rud I, Grimmer S, Sigl S, Narvhus J, Sahlstrøm S (2012) Improved bioavailability of dietary phenolic acids in whole grain barley and oat groat following fermentation with probiotic Lactobacillus acidophilus, Lactobacillus johnsonii, and Lactobacillus reuteri. J Agric Food Chem 60: 6369-6375

19. Bover-Cid S, Holzapfel WH (1999) Improved screening procedure for biogenic amine production by lactic acid bacteria. Int J Food Microbiol 
53: $33-41$

20. Le B, Yang SH (2018) Effect of potential probiotic Leuconostoc mesenteroides FB111 in prevention of cholesterol absorption by modulating NPC1L1/PPAR $\alpha /$ SREBP-2 pathways in epithelial Caco-2 cells. Int Microbiol: 1-9

21. Oyaizu M (1986) Studies on products of browning reaction. The Japanese journal of nutrition and dietetics 44: 307-315

22. Lister E, Wilson P (2001) Measurement of total phenolics and ABTS assay for antioxidant activity (personal communication). Crop Research Institute, Lincoln, New Zealand: 235-239

23. Le B, Yang SH (2018) Isolation of Weissella strains as potent probiotics to improve antioxidant activity of salted squid by fermentation. J Appl Biol Chem 61: 93-100

24. Brand-Williams W, Cuvelier M-E, Berset C (1995) Use of a free radical method to evaluate antioxidant activity. LWT-Food science and Technology 28: 25-30

25. Marcocci L, Maguire JJ, Droylefaix MT, Packer L (1994) The nitric oxide-scavenging properties of Ginkgo biloba extract EGb 761. Biochem Biophys Res Commun 201: 748-755

26. Gulcin İ, Buyukokuroglu ME, Kufrevioglu OI (2003) Metal chelating and hydrogen peroxide scavenging effects of melatonin. J Pineal Res 34: 278-281

27. Michelon D, Tachon S, Ebel B, De Coninck J, Feron G, Gervais P, Yvon M, Cachon R (2013) Screening of lactic acid bacteria for reducing power using a tetrazolium salt reduction method on milk agar. J Biosci Bioeng 115: 229-232

28. Xing J, Wang G, Zhang Q, Liu X, Gu Z, Zhang H, Chen YQ, Chen W (2015) Determining antioxidant activities of lactobacilli cell-free supernatants by cellular antioxidant assay: a comparison with traditional methods. PLoS One 10: e0119058

29. Suzuki Y, Kosaka M, Shindo K, Kawasumi T, Kimoto-Nira H, Suzuki C (2013) Identification of antioxidants produced by Lactobacillus plantarum. Biosci Biotechnol Biochem 77: 1299-1302

30. Oliveira MdS, Cipolatti EP, Furlong EB, Soares LdS (2012) Phenolic compounds and antioxidant activity in fermented rice (Oryza sativa) bran. Food Science and Technology 32: 531-537

31. Mathew S, Abraham TE (2004) Ferulic acid: an antioxidant found naturally in plant cell walls and feruloyl esterases involved in its release and their applications. Crit Rev Biotechnol 24: 59-83

32. Jung TD, Shin GH, Kim JM, Choi SI, Lee JH, Lee SJ, Park SJ, Woo KS, Oh SK, Lee OH (2017) Comparative analysis of $\gamma$-Oryzanol, $\beta$-Glucan, total phenolic content and antioxidant activity in fermented rice bran of different varieties. Nutrients 9: 571

33. Wu TY, Tsai CC, Hwang YT, Chiu TH (2012) Effect of antioxidant activity and functional properties of chingshey purple sweet potato fermented milk by Lactobacillus acidophilus, L. delbrueckii subsp. lactis, and L. gasseri strains. J Food Sci 77: M2-M8 